\title{
A PROFISSIONALIZAÇÃO POLÍTICA NO BRASIL: A EXPERIÊNCIA DO RECRUTAMENTO DOS ASSESSORES DE GABINETES PARLAMENTARES PELA VIA DO CONCURSO PÚBLICO
}

Elton Adriano Siebre Barbosa ${ }^{1}$

Letícia Batista Mathias ${ }^{2}$

Thiago Sousa Jorge ${ }^{3}$

Audren Marlei Azolin (orientadora) ${ }^{4}$

\begin{abstract}
Resumo
Este comunicado visa apresentar os resultados, ainda parciais, de uma pesquisa em andamento que trata da profissionalização política, a partir da profissionalização dos assessores de gabinetes parlamentares, que surgem aqui enquanto o objeto de pesquisa. Temos como problema de pesquisa: existe mercado de trabalho para contratação de assessores parlamentares a partir de critérios de competências e habilidades específicas (qualificação profissional)? Os objetivos da pesquisa são: 1) apresentar as vagas ofertadas para assessores parlamentares; 2) apresentar os principais cursos e conteúdos abordados para qualificação de assessores parlamentares e 3) apresentar os movimentos institucionalizados de renovação política ligados à profissionalização da representação política. A metodologia utilizada é de natureza exploratória, a partir de uma estratégia metodológica predominantemente qualitativa. As fontes foram sites de cursos, vagas de emprego e de novos movimentos pela renovação na política. Na condição de pesquisa exploratória, não partimos de nenhuma hipótese. A pesquisa revelou: 1) que há experiência de recrutamento pela via do concurso público, que embora ainda embrionário no Brasil, não são fatos isolados, mas fazem parte de movimentos institucionalmente organizados pela renovação na política; 2) o recrutamento de assessores qualificados não é uma prática recente, o que surge como novo elemento é o recrutamento via concurso público e 3) o recrutamento via concurso público faz parte da retórica política atrelada aos princípios da administração pública, especialmente os princípios da eficiência e da impessoalidade. Uma vez que são princípios ligados à administração pública e não aos assessores parlamentares. Quando se trata de profissionalização política (político profissional de carreira), duas variáveis independentes assumem grande importância: 1) características distintivas do político profissional e 2) os partidos políticos enquanto espaço institucional de recrutamento. Assim, este comunicado trata de uma terceira variável, ainda pouco explorada, a profissionalização do staff dos gabinetes parlamentares. Esta é a nossa contribuição para literatura.
\end{abstract}

Palavras-Chave: Profissionalização política; Recrutamento; Assessores parlamentares; Mercado de trabalho; Carreira política.

\section{INTRODUÇÃO}

\footnotetext{
${ }^{1}$ Centro Universitário Internacional Uninter, e.adrianosb@outlook.com, ORCID 0000-0002-0006-6793.

${ }^{2}$ Centro Universitário Internacional Uninter, leticiabmathias8@hotmail.com, ORCID 0000-0002-0595-5119

${ }^{3}$ Centro Universitário Internacional Uninter, mailto:tsousa@protonmail.com, ORCID 0000-0002-7928-1444

${ }^{4}$ Centro Universitário Internacional Uninter, audren.a@uninter.com.
} 
Este artigo apresenta resultados ainda parciais de uma pesquisa em andamento que trata do recrutamento de assessores políticos de gabinetes parlamentares. Desta forma, este artigo se insere no estudo sobre a profissionalização política no Brasil. Uma das variáveis mais mobilizadas na Ciência Política para explicar essa profissionalização é o recrutamento político via partido (Perissinotto; Veiga, 2014, p. 51). Isso confere ao recrutamento político o status de objeto de pesquisa por excelência desta ciência.

No entanto, entendemos ser importante pesquisar outra variável, pouco estudada, para explicar a profissionalização política: o staff do gabinete parlamentar, ou seja, os assessores parlamentares. Assim, estamos tratando, como nos ensina Carlomagno (2019, p. 2), de uma "assessoria de natureza política, no caso do Brasil refere-se a posições de cargos de comissão - com escolha discricionária por parte do parlamentar - e trabalha diretamente nos gabinetes legislativos".

A questão de forma mais ampla que surge é a respeito da possibilidade do recrutamento dos assessores parlamentares de livre nomeação e provimento, se basear em critérios técnicos. Tomando emprestada uma questão colocada por Carlomagno (2019, p. 11): “[...] será que podemos falar em profissionalização do staff, quando se trata de cargos comissionados? ”.

Os objetivos deste artigo são: 1) identificar vagas ofertadas em gabinetes parlamentares, 2) identificar a existência de cursos que qualificam para o assessoramento parlamentar e 3) identificar movimentos de renovação política que defendem a profissionalização na política.

É importante distinguir, para efeito desta pesquisa, profissionalização política de profissionalização legislativa. Essa distinção é importante para compreendermos a profissionalização política. A primeira “[...] é o movimento de ampliação da participação dos políticos profissionais [...]" (Carlomagno, 2019, p. 4), é "' aquele que dedica toda, ou uma grande parte, de sua atividade de trabalho à política e dela retira sua principal fonte de subsistência"” (Panebianco, 2005, Apud Carlomagno, 2019, p. 4). Por sua vez, “a profissionalização legislativa se refere essencialmente, [...] às capacidades institucionais da Casa legislativa e de seus membros" (Carlomagno, 2019, p. 4). Em outras palavras,

Profissionalização legislativa remete, portanto, a como as casas legislativas adotam práticas e incentivos que favorecem ou tendem a levar a práticas mais profissionalizadas, sendo a existência do staff apenas um desses elementos. No modelo analítico de Fish e Kroenig são elencadas 32 variáveis. As assessorias parlamentares são apenas duas delas. A profissionalização legislativa pode inclusive ser encarada, como posto no argumento de Thad Kousser, como um movimento anterior à profissionalização política e que leva a esta (Carlomagno, 2019, p.4). 
Assim, a profissionalização dos assessores parlamentares é uma condição importante para profissionalização política, sobretudo, quando:

[...] entendermos que o mandato legislativo não depende somente do mandatário, mas também do corpo de indivíduos que os assessoram, provendo informações e aconselhando na tomada de decisões, o conceito mais amplo de profissionalização do mandato legislativo [...] (Carlomagno, 2019, p. 2).

Metodologicamente, a pesquisa é qualitativa e exploratória, o que não impede de adotarmos em alguns momentos uma estratégia mais quantitativa para melhor sofisticar a análise. No estudo sobre profissionalização política, há modelos analíticos tradicionalmente usados, que adotam abordagens sociológicas e institucionalistas (Carlomagno, 2019; Oliveira, 2009). De forma mais clara, existem metodologicamente três abordagens:

i) institucionalista (regras de contratação conformam a configuração que as assessorias poderão assumir); ii) sociológico-política (características de perfil e vias de recrutamento dos assessores); e iii) organizacional-decisória (formas hierárquicas das estruturas organizacionais e o papel do staff nos processos decisórios internos do gabinete) (Carlomagno, 2019, p. 2).

A opção pela abordagem institucionalista, se explica, uma vez que o foco da investigação aqui empreendida é a identificação e análise de critérios adotados para seleção de assessores parlamentares fora da via da indicação política.

$\mathrm{O}$ artigo está dividido em três seções. Na primeira apresentamos os movimentos pela renovação na política que trazem uma narrativa pró-profissionalização na política. Na segunda seção consta os cursos que visam qualificar para o mundo político e seus respectivos conteúdos. Por fim, a terceira seção, quando são apresentadas algumas contratações de assessores para gabinetes parlamentares pela via do concurso público.

\section{OS MOVIMENTOS PELA RENOVAÇÃO POLÍTICA}

Na segunda década do século XXI diversas organizações pela renovação na política surgiram no Brasil. E um dos elementos centrais é a qualificação para atuar no mundo político. Estes movimentos corroboram para tese que defendemos: do aumento da profissionalização dos assessores 
de parlamentares no Brasil. São movimentos, ONGs, empresas e associações, histórias e membros comuns ou diferentes entre si, que carregam como missão melhorar a política brasileira.

Foram analisadas algumas das várias organizações através de seus respectivos sites, notícias e consulta a membros com objetivo de entender de que forma as mesmas contribuem com a profissionalização política no país, em específico a profissionalização do staff parlamentar. Identificamos cinco organizações dessa natureza: Legisla Brasil, Acredito, RenovaBR, Rede de Ação Política pela Sustentabilidade (RAPS) e Politize.

O Legisla Brasil é uma sociedade sem fins lucrativos que atua desde o ano de 2018 "acelerando" mandatos, ou seja, a organização capacita tecnicamente profissionais interessados e os conectam com o poder legislativo (Senado, Câmaras e Assembleias) e oferecem para os políticos uma gestão completa para seu gabinete (desenho de equipe, seleção de talentos, monitoramento de performance e planejamento estratégico de mandato).

Segundo o site, a organização já prestou serviços para mais de 25 políticos (entre deputados, senadores e vereadores), dentre eles Felipe Rigoni, Tábata Amaral e Alessandro Vieira, que veremos ligados também a outras instituições.

O Movimento Acredito é um movimento político fundado em 2017 pelos atuais deputados federais Tábata Amaral e Felipe Rigoni, já citados anteriormente. O Acredito busca "uma renovação de princípios, práticas e pessoas" com "uma prioridade: superar nossas profundas desigualdades". (Movimento Acredito, 2020). O movimento atua de forma suprapartidária, isto é, que agrega diferentes partidos, mas que não se subordina a nenhum deles. Há uma divisão em núcleos (nacional, estadual e municipal) onde são alocadas as lideranças, mobilizadores e voluntários.

Não fica claro, pelo menos para quem acessa o site, se são oferecidos cursos ou capacitações para possíveis interessados (existe somente uma menção de possível treinamento caso haja interesse de abrir um núcleo estadual). Ocorrem reuniões frequentes entre membros, mas isso tende a variar conforme a agenda do núcleo. Ademais, o financiamento do movimento é feito somente por doações de pessoas físicas.

O RenovaBR se denomina como a maior escola de democracia e de políticos do Brasil. Foi fundada em outubro de 2017 por iniciativa do empresário Eduardo Moraes. A escola teve até o momento, mais de 35 mil pessoas interessadas onde, dentre elas, mais de 2 mil foram formadas pela instituição, inclusive os Deputados já citados anteriormente Felipe Rigoni e Tábata Amaral, além do Senador Alessandro Vieira. 
A organização possui uma atuação completa com as "pessoas comuns" (o público das atividades do RenovaBR) que são selecionadas através de um rigoroso processo com 6 diferentes etapas. Depois de selecionadas, essas pessoas (agora alunos Renova) iniciam uma formação com uma série de profissionais de diversas áreas de atuação e ideologias, com o objetivo de qualificar "pessoas comuns para uma política fora do comum”. ( RenovaBR, 2020)

Com a formação oferecida, os alunos saem mais capacitados para a disputa eleitoral e, consequentemente, para cargos políticos em geral. Dentro do manifesto da instituição, fica explícito o desejo de renovação política, renovação essa que carregam no nome.

A Rede de Ação Política pela Sustentabilidade (RAPS) se trata de uma organização suprapartidária fundada em maio de 2012 com a missão de contribuir para a melhora da qualidade da democracia no Brasil. A organização tem como objetivo conectar, desenvolver e apoiar lideranças políticas comprometidas com a sustentabilidade.

Atualmente, a RAPS possui uma rede com 677 líderes, distribuídos por todo o território brasileiro. Esses membros são selecionados através do "Programa de Líderes RAPS", onde passam por um processo avaliativo e são oferecidos módulos de formação e material de estudos, além de debates sobre temas variados referente à participação política.

Ademais, a RAPS não se considera um MRP, isto é, um movimento de renovação política, pois possui organização, governança e estrutura própria definida e, também não atua com a "renovação política" visto que a instituição carrega como propósito o preparo de líderes políticos, independendo de sua experiência prévia.

O Politize é uma ONG que busca criar uma nova geração de pessoas conscientes e comprometidas com a democracia através da educação política, dentro e fora da internet. Foi fundada no ano de 2015 como um instituto de educação política

A organização já impactou 25 milhões de usuários únicos (de forma online), formou 35 mil pessoas presencialmente e esteve presente em 127 municípios brasileiros.

Três pilares norteiam as ações da organização: 1) a produção de conteúdo, onde através de suas plataformas levam informações e promovem debates com objetivo de mostrar a importância da participação política; 2) a formação de líderes locais, os embaixadores, que passam por cursos com objetivo de capacitá-los para a protagonização em seus ciclos sociais; e 3) a transformação de escolas e comunidades, através dos embaixadores que atuam em diversos locais distintos levando conhecimento. 
No site da organização são ofertados cursos gratuitos sobre temas políticos em geral com a proposta de capacitar cidadãos civicamente. Notadamente, os movimentos acima tratam da capacitação para atuar na política que, embora abarque o staff parlamentar, transcendem o cargo/função de assessor parlamentar, isto é, trata de uma capacitação profissional de atuação na política mais abrangente. No entanto, existem cursos específicos para qualificar para as atividades de assessoramento parlamentar? Este será o tema da próxima seção.

\section{QUALIFICAÇÃO PARA ATUAR NO MERCADO DE ASSESSORIA PARLAMENTAR}

A questão que levantamos nesta seção é: para que criar cursos de qualificação de assessores parlamentares quando os gabinetes parlamentares acolhem pessoas recrutadas por indicação política? A questão que colocamos reflete o pensamento do senso comum: indicação política versus indicação técnica. No entanto, pesquisas recentes sobre o staff parlamentar, indica um tipo híbrido. De acordo com Carlomagno (2019, p. 12), “O fato de ser uma imbricação entre um trabalho técnico, mas com indicação política, coloca o staff parlamentar brasileiro [...] em ambivalente posição, uma balança entre aspectos de domínio técnico e de relações políticas”. Neste sentido,

\footnotetext{
A burocracia brasileira, tal qual a maior parte dos sistemas administrativos contemporâneos, pode ser classificada em dois grupos. O primeiro é formado pela burocracia efetiva, mais estável, e cujos ocupantes são definidos por meio de alguma modalidade de seleção competitiva, a exemplo dos concursos públicos. O segundo grupo é a burocracia constituída por nomeações de caráter discricionário, que detém, comparativamente, mais poder administrativo e capacidade de influir na gestão das políticas, e mantém, em média, conexões mais estreitas com a esfera político-partidária. (Lopez, 2015, p. 11)
}

Notamos, assim, que os assessores parlamentares fazem parte de uma categoria que Carlomagno chamou de burocracia política que apresenta uma dupla característica: indicação política e atributo técnico. Este último justifica a criação de cursos que qualifiquem para as atividades de assessoramento parlamentar.

Identificamos diversos cursos, destacamos alguns: Curso de Assessor Legislativo Municipal oferecido pela Buzzero, Curso de Redes Sociais para Gabinete Parlamentar em Brasília, oferecido pela União dos Vereadores do Brasil, Minicurso de Assessoria de Comunicação Parlamentar oferecido pela Ordem dos Advogados do Brasil (OAB) de Pernambuco, Curso de Especialização em Assessoria Política oferecido pela Universidade de Brasília (UNB), Pós-graduação em Assessoria 
Parlamentar oferecido pela Faculdade Republicana, Curso de Graduação em Assessoria Política oferecido pela Universidade de Caxias do Sul, Curso Assessoria Parlamentar oferecido pelo Bravo Brasil, Curso de Assessoria Parlamentar oferecido pela Associação Brasileira de Formação e Desenvolvimento Social, Curso de Especialização em Política e Representação Parlamentar oferecido pela Câmara dos Deputados e Câmara Legislativa do DF.

Analisando os sites dos cursos, podemos dizer que ao contrário do que se pensa, a assessoria parlamentar pode ser encontrada em diversos segmentos da sociedade. Por isso, é necessária a qualificação do assessor para que possa trazer a sua experiência profissional e acadêmica para o gabinete político e contribuir com melhorias para a sociedade.

O assessor parlamentar transita pelos bastidores do poder, auxiliando políticos que tenham mandato nas casas legislativas, seja participando de reuniões, seja analisando aspectos técnicos dos projetos, interagindo com outros gabinetes, áreas de comunicação e a sociedade em geral. O assessor parlamentar pode atuar em diferentes âmbitos, como no Executivo Municipal, Estadual e Federal, no Legislativo Municipal, Estadual e Federal, em campanhas eleitorais, empresas, movimentos sociais, junto a partidos políticos, entre outros.

Verificamos a necessidade de maior divulgação à sociedade em geral sobre a função do assessor parlamentar com vistas a despertar maior interesse dos jovens para atuarem neste segmento de mercado de trabalho, proporcionando uma maior renovação dos profissionais e consequente modernização do gabinete parlamentar. Ainda considerando os sites dos cursos, abaixo elencamos as atividades dos assessores parlamentares:

- Assessoramento técnico e político, interno e externo, nas questões de sua área de atuação ou área de conhecimento;

- Planejamento e execução das ações legislativas e políticas do Deputado;

- Distribuição de tarefas;

- Supervisão dos grupos de trabalho;

- Assessoramento do processo legislativo;

- Elaboração de pareceres;

- Elaboração de Projetos de Lei e de outras proposições legislativas;

- Elaboração de Voto em Separado;

- Análise de Projeto de Lei;

- Estabelecimento de interlocução do Deputado com órgãos do Judiciário, do Ministério Público, do Poder Executivo e com entidades e movimentos organizados da sociedade civil; 
- Tratar de assuntos relacionados à contratação, exoneração, frequência, férias e outros assuntos dessa natureza;

- Cuidar das emissões e reservas de passagens aéreas;

- Elaborar pronunciamentos;

- Prestar assistência a autoridades em compromissos oficiais;

- Acompanhar matérias legislativas e as publicações oficiais de interesse do parlamentar.

A grade utilizada para a formação do conteúdo programático dos cursos de qualificação de assessoria parlamentar atende a alguns aspectos de preparo técnico e de informação que são necessários ao bom entendimento da função que este profissional irá exercer. Os cursos oferecidos apresentam similaridades no conteúdo programático, de forma a atender os anseios dos interessados. Os futuros profissionais da área podem optar em fazer cursos de graduação, pós-graduação e cursos de especialização que requerem menor tempo para conclusão. O conteúdo programático abrange as seguintes áreas/matérias:

- Administração Pública;

- História do Parlamento;

- Instituições Políticas;

- Política e Processo Legislativo;

- Teoria do Processo Legislativo;

- Planejamento e Orçamento Público;

- Comunicação;

- Mídias sociais;

- Planejamento estratégico;

- Marketing político;

- Sistema político e eleitoral;

- Políticas públicas e legislação;

- Liderança;

- Estudos em sociologia e antropologia;

- Ciências Políticas;

- Tecnologia da Informação;

- As assessorias parlamentares nos órgãos reguladores;

- Atribuições e papéis da assessoria parlamentar;

- Como implantar uma assessoria parlamentar; 
- Democracia e representação política: dos gregos às redes sociais;

- Fiscalização e transparência;

- Compliance aplicado à atividade política;

- Mandato digital;

- Judiciário e a atividade legislativa;

- Accountability e controles democráticos;

- Finanças públicas e processo orçamentário;

- Metodologia de pesquisa;

- Seminários em assessoria política, governo e políticas públicas;

- O relacionamento com a grande imprensa, a imprensa oficial e os assessorados;

- A importância das redes sociais e sua correta utilização;

- Gestão de crises;

- Criando conteúdo próprio e de interesse público;

- Gerenciamento de Fan Pages / Facebook;

- Gerenciamento de Distribuição de conteúdos via Whatsapp, Email Marketing e Instagram;

- Ferramentas e campanhas de impulsionamento;

- Considerações básicas para construção de reputação política nas redes sociais;

- Formatos de publicação para obter maior alcance.

Vimos nesta seção que existem cursos de qualificação de assessores parlamentares. No entanto, a existência de tais cursos somente se justifica se estiver em curso, a contratação de assessores parlamentares com atributos técnicos. Desta forma, na próxima seção discorremos a respeito de contratação de assessores a partir desses atributos.

\section{RECRUTAMENTO DE ASSESSORES PARLAMENTAReS PELA VIA DO CONCURSO PÚBLICO}

Alguns exemplos de recrutamento de assessores parlamentares foram identificados e chamam atenção, já que a natureza da ocupação, em certa medida, se caracteriza pela combinação de indicação política e atributos técnicos. O recrutamento via concurso público parece estar descaracterizando a indicação política. Será este um indício do que se tem denominado de movimento de renovação na política? 
Uma das representantes desse movimento é a deputada federal Tábata Amaral (PDT) que em sua coluna no Nexo disse o seguinte:

\begin{abstract}
Essa renovação de práticas durante a campanha me permitiu ser eleita sem amarras e me deu liberdade para seguir inovando no mandato. Junto com o deputado federal eleito Felipe Rigoni (PSB-ES) e o senador eleito Alessandro Vieira (PPS-SE), eu farei uma gestão compartilhada do processo parlamentar. Pretendemos criar uma startup política, um laboratório para inovações no Congresso, que nos permita compartilhar algumas vagas, como a de cientista de dados, econometrista e fiscalizador, as quais, tratadas de forma isolada, representariam um custo muito alto para um único gabinete (Amaral, 2019).
\end{abstract}

Para a deputada, a renovação política passa por novas práticas organizativas do gabinete parlamentar, novos experimentos em termos de treinamento político, bem como profissionais de diversas áreas do conhecimento na situação de assessor parlamentar. E quanto ao recrutamento dos assessores? Segundo a deputada,

\footnotetext{
Para preencher as vagas dos gabinetes individuais e do gabinete compartilhado, optamos por realizar um processo seletivo aberto, que teve 16.047 inscritos no total. Um outro benefício da gestão compartilhada é que nos permitiu, sem perda de qualidade, economizar parcela importante das verbas parlamentares. Essas são ideias gestadas no ambiente do Acredito, movimento de renovação política do qual sou cofundadora. (Amaral, 2019).
}

De acordo com a deputada, o novo modelo organizativo de gabinete parlamentar, o recrutamento de parte dos assessores do gabinete compartilhado e individual, deu-se por um tipo de concurso público. Chama atenção a quantidade de candidatos na ordem de 16.047. Perderia essa forma de recrutamento o viés político?

A deputada faz uma revelação interessante: seu estilo de condução do gabinete parlamentar foi gestado no Movimento Acredito cujo mote é a renovação na política. Desta forma, o crescimento de movimentos pela renovação na política, que se apresenta como defesa de qualificação profissional para atuar na política, pode estar trazendo um mercado de trabalho na política que exigirá qualificação específica para atuar no segmento de assessoramento político.

Ao iniciar a busca exploratória para esboçar um panorama de como estão distribuídas as oportunidades de trabalho no campo da assessoria parlamentar, dentro de gabinetes parlamentares, nos deparamos rapidamente com uma enorme dificuldade de análise, gerada, em grande conta pelo 'tradicionalismo' político brasileiro na escolha de assessores. Em grande soma, a maioria esmagadora das vagas em gabinetes parlamentares é composta de indicações baseadas em laços de proximidade e confiança, em detrimento de conhecimento técnico. 
Portanto, uma das diretrizes deste estudo foi focar em vagas abertamente públicas, onde qualquer pessoa poderia se candidatar a fazer parte do processo seletivo. Desta forma, ao reduzir o escopo de análise para estas vagas públicas, transformamos a dificuldade, descrita acima, em um filtro para análise objetiva.

A presença de novos movimentos focados em renovação de políticos e da prática política, a maior parte deles com orientação liberal e criado após as crises de 2013, tem cumprido parte da função de trazer à tona a problemática tradicional de nomeações personalísticas e os danos que isso gera à própria República.

Na esteira das ações disruptivas, o Movimento Acredito lançou duas novidades, através de uma ação articulada entre os três parlamentares que o grupo ajudou a eleger: um processo de seleção unificada e a livre circulação desses membros entre os respectivos gabinetes, a fim de otimizar o processo de criação de políticas públicas. As vagas envolvem todos os ramos necessários em um gabinete: analistas políticos, assessores jurídicos, cientistas de dados, assessores fiscais, entre outros.

Outro fator a se levar em consideração é que, apesar de políticos liberais levantarem essa bandeira da escolha técnica e impessoal da assessoria, não é verdade que progressistas e socialistas ignorem este tipo de escolha. Portanto, foi constatado que há disponibilidade de vagas públicas e técnicas, desde gabinetes de políticos da esquerda à direita.

Todavia, se considerarmos que este movimento de profissionalização nos gabinetes era, há alguns anos atrás, praticamente inexistentes, é de se considerar a presença crescente de vagas a partir do recrutamento público extremamente positiva.

O quadro abaixo apresenta uma lista fazendo referência às vagas mais comuns disponíveis para profissionais especialistas em diversas áreas do conhecimento. (Régis, 2019)

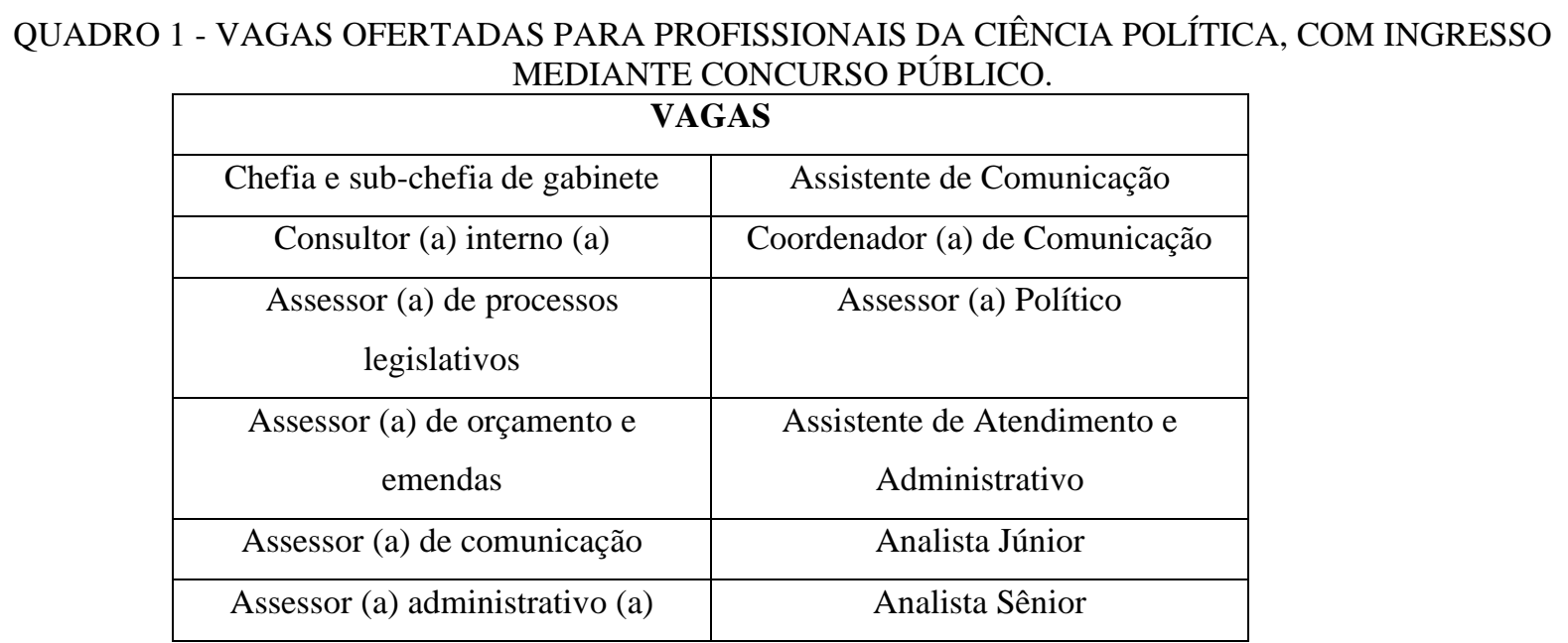




\begin{tabular}{|c|c|}
\hline Secretário (a) parlamentar & Assessor (a) Jurídico \\
\hline Assessor(a) de Relacionamento & Cientista de Dados \\
\hline Assessor (a) de Fiscalização & Coordenador (a) de Agenda Política \\
\hline
\end{tabular}

FONTE: os próprios autores a partir de Régis 2019

No sentido de melhor esclarecer, a partir de dados, as vagas ofertadas para contratação de assessores para gabinetes parlamentares, abaixo apresentamos três gráficos. O gráfico 1 apresenta dados referentes a contratação de assessores parlamentares, via concurso público, por casa legislativa. Neste gráfico os dados estão apresentados em números absolutos, porque não é possível comparar proporcionalidades entre casas legislativas diferentes, com quantidades de parlamentares diferentes.

GRÁFICO 1: EXPERIÊNCIA DE CONTRATAÇÃO VIA CONCURSO PÚBLICO POR CASA LEGISLATIVA

\section{Experiência de contratação via concurso público por casa legislativa}

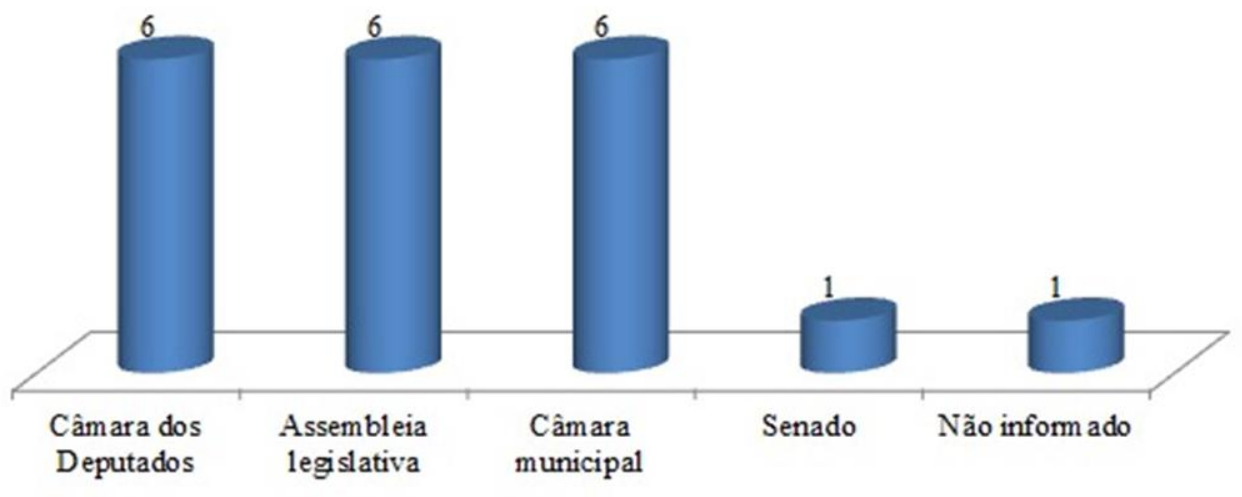

FONTE: os próprios autores

Do total de vagas ofertadas, destaca-se a Câmara dos Deputados, Assembleias Legislativas e as Câmaras Municipais. No entanto, é importante ressaltar, que o maior destaque é da Câmara dos Deputados, pois nela concentra a maior quantidade tendo em vista que existem diversas assembleias legislativas e câmaras de vereadores no Brasil. Considerando as três esferas legislativas (federal, estadual e municipal), a Câmara dos Deputados foi responsável por um terço das contratações via concurso público realizadas no Brasil.

O gráfico 2 apresenta dados relativos às experiências de contratação via concurso público por Unidade da Federação. 
GRÁFICO 2: EXPERIÊNCIA DE CONTRATAÇÃO VIA CONCURSO PÚBLICO POR UNIDADE DA FEDERAÇÃO

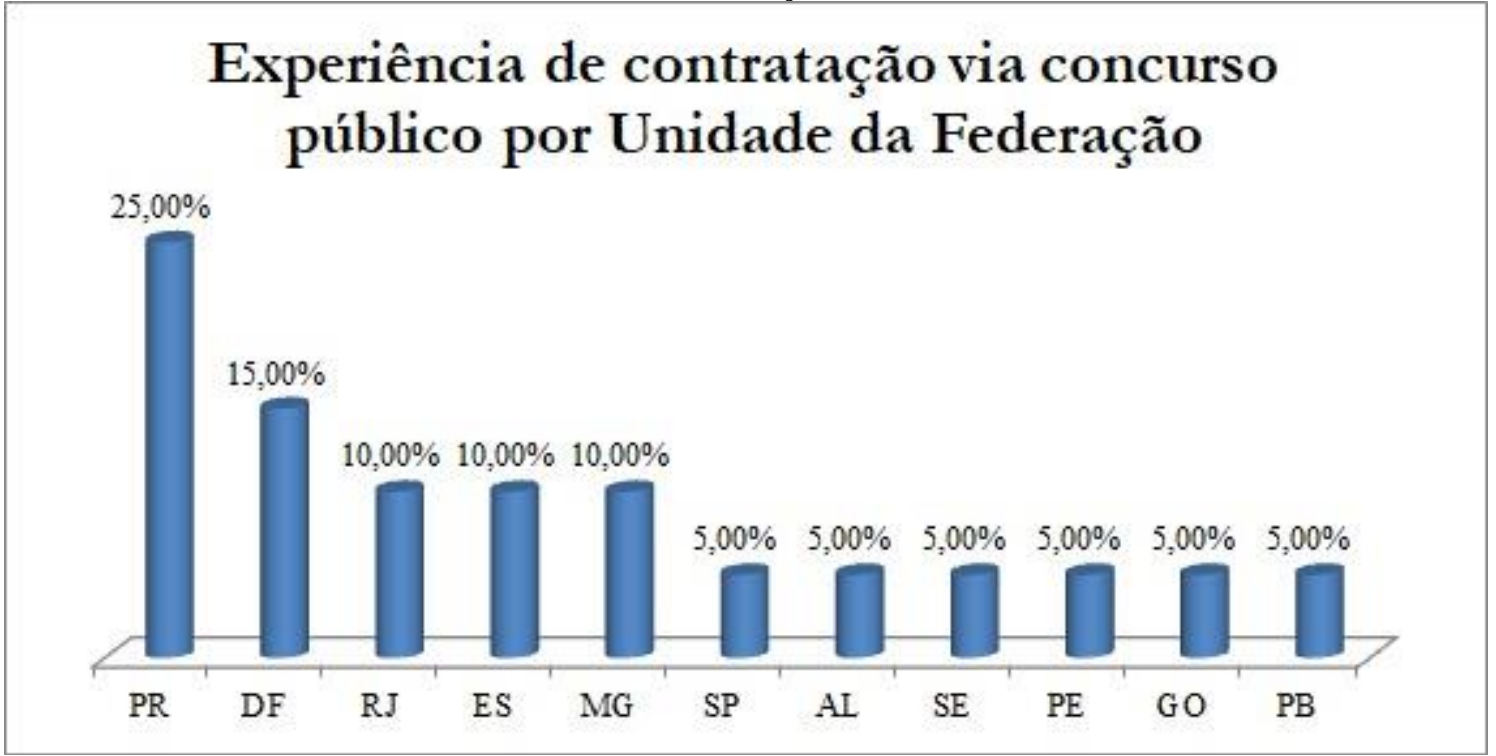

FONTE: os próprios autores

O estado que mais se destaca é o Paraná responsável por $25 \%$ das contratações via concurso público realizadas no Brasil. Em segundo lugar o Distrito Federal responsável por 15\% das contratações, seguidos pelo Rio de Janeiro, Espírito Santo e Minas gerais com 10\% cada. Chama atenção o estado de São Paulo, com a maior quantidade de parlamentares do Brasil, não figurar entre os estados com maior quantidade de contratações. O gráfico 3 apresenta dados referentes à contratação de assessores via concurso público por partido.

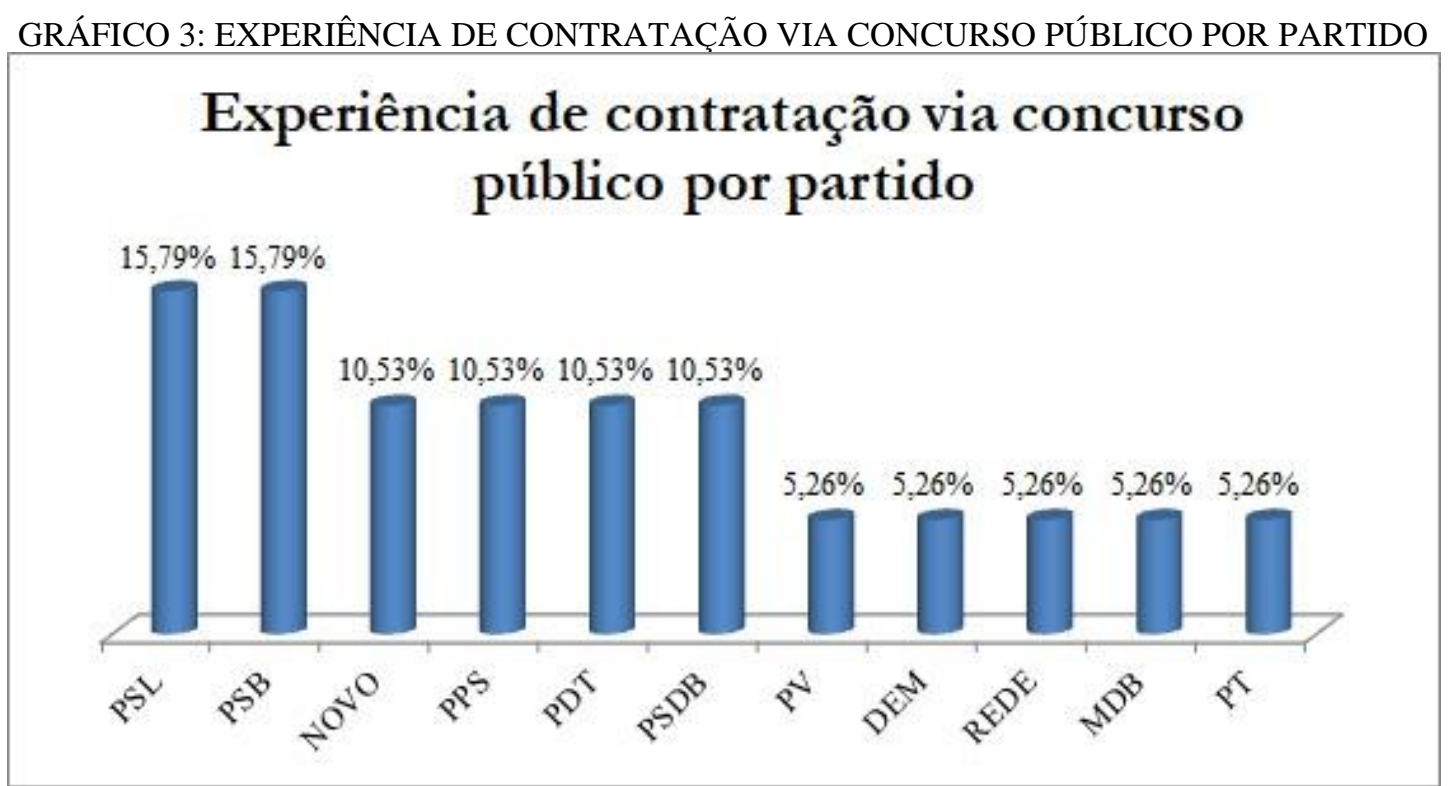

FONTE: os próprios autores 
Os partidos que mais se destacam são o PSL e o PSB responsáveis por 15,79\% cada. Chama atenção o PSB, um partido localizado à esquerda do espectro político, uma vez que contratações mediante atributos profissionais parece ser uma orientação ideológica liberal. Na segunda colocação estão o Novo, PPS, PDT e o PSDB, com 10,53\% cada. Aqui temos outro destaque, o PDT. Este pode estar bem colocado graças à deputada Tábata Amaral, algo ainda para ser investigado.

\section{CONSIDERAÇÕES FINAIS}

O problema central deste artigo é o de identificar se há possibilidades de profissionalização do staff dos gabinetes parlamentares, uma vez que tradicionalmente tais assessores são recrutados por critérios político-partidários. Nossa investigação identificou movimentos suprapartidários de renovação política com a agenda de profissionalização na política. Esses movimentos visam qualificar lideranças políticas para atuarem na política de forma profissionalizada.

Nossa investigação também identificou cursos destinados à qualificação profissional de pessoas para atuarem na política, de forma especial, assessores parlamentares. A existência de movimentos políticos de renovação política e os cursos de profissionalização para atuação na política, se não revela de forma enfática a profissionalização do staff parlamentar, revela uma tendência de profissionalização do staff. Essa tendência é confirmada pelos casos, embora poucos, de contratação de assessores parlamentares pelo recrutamento pela via do concurso público.

Consultada a literatura especializada, vimos que no Brasil o recrutamento dos assessores se dá pelo duplo critério: atributos técnicos e indicação política. Por fim, nossa investigação revelou experiências de contratação pela via do concurso público. Essa realidade que se revela abre espaço para uma agenda de pesquisa dedicada ao recrutamento do staff parlamentar.

\section{REFERENCIAS}

A Gazeta. Vereador de Vitória abre vaga para contratar estagiário. Disponível em: https://www.agazeta.com.br/concursos/vereador-de-vitoria-abre-vaga-para-contratar-estagiario0419; Acesso em: 15 de junho de 2020.

ALBUQUERQUE, Maria dos Remédios Santos. Competências do assessor parlamentar da Câmara Legislativa do Distrito Federal. 2009. TCC (Pós-graduação em Gestão da Educação Corporativa) - Universidade Gama Filho, 2009. Disponível em: 
https://portal.tcu.gov.br/lumis/portal/file/fileDownload.jsp?fileId=8A8182A24F0A728E014F0AE0 32206486; Acesso em: 09 de junho de 2020.

AMARAL, Tabata. Como pretendo renovar, de fato, a política. Nexo. Seção Tribuna, fev, 2019. Disponível em: <https://www.nexojornal.com.br/colunistas/tribuna/2019/Como-pretendo-renovarde-fato-a-pol\%C3\%ADtica> ; Acesso em 19 jun. 2020.

Assembleia Legislativa de Alagoas. Prorrogadas as inscrições do processo seletivo para vagas em gabinete parlamentar. Disponível em: https://www.al.al.leg.br/comunicacao/noticias/prorrogadasas-inscricoes-do-processo-seletivo-para-vagas-em-gabinete-parlamentar; Acesso em: 15 de junho de 2020.

Boletim Unicap. Curso orienta como fazer assessoria de comunicação para parlamentares. Disponível em: http://www.unicap.br/assecom1/curso-orienta-como-fazer-assessoria-decomunicacao-para-parlamentares/; Acesso em: 09 de junho de 2020.

Buzzero.com. Curso Online de Assessor Legislativo Municipal. Disponível em: https://www.buzzero.com/ciencias-humanas-81/governo-e-politica-93/curso-online-assessorlegislativo-municipal-com-certificado-30065; Acesso em: 09 de junho de 2020.

Câmara dos Deputados. 56 ${ }^{\mathrm{a}}$ Legislatura (2019-2023) - Gestão de pessoas do Gabinete. Disponível em: $\quad$ https://www2.camara.leg.br/comunicacao/camara-noticias/camara-destaca/56alegislatura/no-exercicio-do-mandato/verba-de-gabinete/gestao-de-pessoas-do-gabinete ; Acesso em: 09 de junho de 2020.

Câmara dos Deputados. Curso de Especialização em política e representação parlamentar (PRP). Disponível em: https://www2.camara.leg.br/a-camara/programas-institucionais/cursos/posgraduacao/cursos-de-especializacao/cursos-realizados/curso-de-especializacao-em-politica-erepresentacao-parlamentar-prp ; Acesso em: 09 de junho de 2020.

Câmara Municipal de Toledo. Câmara abre seleção a 4 vagas de estágios em gabinetes. Disponível em: https://www.toledo.pr.leg.br/assessoria-de-imprensa/noticias/camara-posta-edital-para-selecaoa-4-vagas-de-estagios-em-gabinetes ; Acesso em: 15 de junho de 2020.

CARLOMAGNO, Márcio. O que podemos responder pesquisando assessorias parlamentares? Agenda de investigação. BIB, São Paulo, n. 88, 2019 (publicada em março de 2019), pp. 1-20. Disponível em: http://anpocs.com/images/BIB/n88/1017666bib88062019.pdf ; Acesso em 29 jan. 2020.

Cursos Abrafordes - Associação Brasileira de Formação e Desenvolvimento Social. Curso Assessoria Parlamentar. Disponível em: https://www.cursosabrafordes.com.br/curso-assessoriaparlamentar ; Acesso em: 09 de junho de 2020.

Cursos Online Bravo Brasil. Curso Assessoria Parlamentar. Disponível em: https://www.cursosonlinebra.com.br/curso19.html ; Acesso em: 09 de junho de 2020. 
Educa+ Brasil. Processo Legislativo e/ou Gestão Parlamentar. Disponível em: https://www.educamaisbrasil.com.br/cursos-e-faculdades/processo-legislativo-eou-gestaoparlamentar ; Acesso em: 09 de junho de 2020.

ELEVE - Portal de Educação à distância da Câmara dos Deputados. Disponível em: https://educacaoadistancia.camara.leg.br/site/ Acesso em: 09 de junho de 2020.

Exame. Deputado do RJ faz processo seletivo para assessores e paga até $\mathbf{R} \$ \mathbf{9 , 8}$ mil. Disponível em: https://exame.com/carreira/confira-as-vagas-para-trabalhar-na-equipe-do-deputado-mais-novodo-rj/; Acesso em: 15 de junho de 2020.

Faculdade Republicana. Pós-Graduação em Assessoria Parlamentar. Disponível em: https://faculdaderepublicana.org.br/assessoria-parlamentar/ ; Acesso em: 09 de junho de 2020.

ILB - Instituto Legislativo Brasileiro. Saberes - Portal de Educação à distância do Senado Federal. Disponível em: https://saberes.senado.leg.br/ ; Acesso em: 09 de junho de 2020.

JC. Políticos fazem processo de seleção para contratar assessores. Disponível em: https://jc.ne10.uol.com.br/canal/politica/pernambuco/noticia/2019/01/27/politicos-fazem-processode-selecao-para-contratar-assessores-369680.php; Acesso em: 15 de junho de 2020.

Jornal da Paraíba. Deputado Estadual da PB abre seleção para contratação de assessores de gabinete. Disponível em: https://www.jornaldaparaiba.com.br/politica/deputado-estadual-da-pbabre-selecao-para-contratacao-de-assessores-de-gabinete.html ; Acesso em: 15 de junho de 2020.

Legisla Brasil. Acelere seu mandato. Disponível em: https://legislabrasil.org/acelere-seu-mandato/ ; Acesso em: 07 de Junho de 2020.

Legisla Brasil. Somos Legisla. Disponível em: https://legislabrasil.org/somos-legisla/ ; Acesso em: 07 de Junho de 2020.

LIVRES. Deputados associados fazem processo seletivo para gabinetes. Disponível em: https://www.eusoulivres.org/noticias/deputados-associados-abrem-processo-seletivo-para-equipesde-gabinete/; Acesso em: 15 de junho de 2020.

LOPEZ, F. Introdução. In: LOPEZ, F. (Ed.). Cargos de confiança no presidencialismo de coalizão brasileiro. Brasília, DF: Ipea, 2015. p. 11-31.

Mais Santos. Deputado oferece vaga para estágio e assessor parlamentar. Disponível em: http://www.maissantos.com.br/brasil/brasil-cotidiano/deputado-oferece-vaga-para-estagio-eassessor-parlamentar/; Acesso em: 15 de junho de 2020.

Movimento Acredito. Movimento Acredito. Disponível em: www.movimentoacredito.org/site/ ; Acesso em: 07 de Junho de 2020.

NOMURA, Bruno. Conheça movimentos de renovação política que vão atuar nas eleições de 2020. O Estado de S. Paulo. São Paulo, 24 de Fev. de 2020. Disponível em: 
https://politica.estadao.com.br/noticias/eleicoes,conheca-movimentos-de-renovacao-politica-quevao-atuar-nas-eleicoes-de-2020,7000317568; Acesso em: 07 de Junho de 2020.

O Hoje.com. Deputado estadual recebe inscrições para vagas de estágios. Disponível em: http://ohoje.com/noticia/politica/n/159382/t/deputado-estadual-recebe-inscricoes-para-vagas-deestagios ; Acesso em: 15 de junho de 2020.

Péricles Régis. Que tal trabalhar na política? Veja gabinetes que estão com processo seletivo aberto. Disponível em: http://periclesregis.com.br/que-tal-trabalhar-na-politica-veja-os-eleitos-queestao-com-processo-seletivo-aberto-em-seus-gabinetes ; Acesso em: 15 de junho de 2020.

POLITIZE! - INSTITUTO DE EDUCAÇÃO POLÍTICA . Ata de reunião de assembleia geral ordinária do Politize!, 2015. Disponível em: https://www.politize.com.br/wpcontent/uploads/2019/03/Estatuto-altera\%C3\%A7\%C3\%B5es-ata-defunda\%C3\%A7\%C3\%A3o.pdf ; Acesso em: 07 de junho de 2020.

Politize!. Quem somos: Conheça as pessoas por trás do Politize! Disponível em: https://www.politize.com.br/quem-somos/; Acesso em: 08 de Junho de 2020.

Politize. Assessor parlamentar: quem é e o que faz? Disponível em: https://www.politize.com.br/assessor-parlamentar-o-que-faz/ ; Acesso em: 09 de junho de 2020.

Portal Pró-legislativo. Curso de redes sociais para gabinete parlamentar em Brasília. Disponível em: http://prolegislativo.com.br/index.php/curso-de-redes-sociais-para-gabinete-parlamentar-embrasilia/ ; Acesso em: 09 de junho de 2020.

RAPS - Rede de Ação Política pela Sustentabilidade. Quem somos. Disponível em: https://www.raps.org.br/quem-somos/ ; Acesso em: 08 de Junho de 2020.

RenovaBR. Quem Somos. Disponível em: https://renovabr.org/quem-somos/ ; Acesso em: 07 de Junho de 2020.

Todos pela Educação. Aprendendo sobre Educação: Todos promove formação em políticas públicas educacionais para assessores parlamentares. Disponível em:

https://www.todospelaeducacao.org.br/conteudo/Aprendendo-sobre-Educacao-Todos-promoveformacao-em-politicas-publicas-educacionais-para-assessores-parlamentares ; Acesso em: 09 de junho de 2020.

UNB - Instituto de Ciência Política (IPOL). Curso de Especialização em Assessoria Política. Disponível em: http://ipol.unb.br/index.php?option=com_content\&view=article\&id=42:cursode-especializacao-em-assessoria-politica\&catid=180\&Itemid=101; Acesso em: 09 de junho de 2020.

Universidade de Caxias do Sul. Assessoria Política: Conheça o novo curso de graduação UCSTEC. Disponível em: https://www.ucs.br/site/noticias/assessoria-politica-conheca-o-novocurso-de-graduacao-ucstec/ ; Acesso em: 09 de junho de 2020. 